\title{
Fish-oil supplementation reduces stimulation of plasma glucose fluxes during exercise in untrained males
}

\author{
Jacques Delarue ${ }^{1 *}$, Francois Labarthe ${ }^{2}$ and Richard Cohen ${ }^{3}$ \\ ${ }^{1}$ Laboratoire Régional de Nutrition Humaine \& EA-948, Médecine 4-Nutrition, CHU Cavale Blanche, \\ F-29200-Brest, France \\ ${ }^{2}$ Pédiatrie R, CHU de Tours F-37044-Tours, France \\ ${ }^{3}$ Radiopharmacie et Radioanalyse, Hôpital Cardio-neurologique F-69003-Lyon, France
}

(Received 10 January 2003 - Revised 27 May 2003 - Accepted 23 June 2003)

\begin{abstract}
The present study examined the effects of a 3-week fish-oil supplementation $(6 \mathrm{~g} / \mathrm{d})$ on the rate of plasma glucose disappearance (Rd glucose), hepatic glucose production (HGP), carbohydrate oxidation and lipid oxidation during exercise. Six untrained males (23 \pm 1 years; $67.6 \pm 2.7 \mathrm{~kg}$ ) performed two $90 \mathrm{~min}$ cycling exercise sessions at $60 \%$ of maximal $\mathrm{O}_{2}$ output separated by $20 \mathrm{~d}$. During the $20 \mathrm{~d}$ before the first test, they ingested $6 \mathrm{~g}$ olive oil/d, then $6 \mathrm{~g}$ fish oil/d during the $20 \mathrm{~d}$ before the second test. Plasma glucose fluxes and lipolysis were traced using 6,6- $\left[{ }^{2} \mathrm{H}_{2}\right]$ glucose and 1,1,2,3,3-[ $\left[{ }^{2} \mathrm{H}_{5}\right]$ glycerol respectively. Substrates oxidation was obtained from indirect calorimetry. At rest HGP and the Rd glucose were similar after olive oil and fish oil (1.83 (SE 0.05) v. 1.67 (SE 0.11) mg/kg per min). During exercise, fish oil reduced the stimulation of both the Rd glucose (5.06 (SE 0.23) v. 6.37 (SE 0.12) $\mathrm{mg} / \mathrm{kg}$ per min; $P<0.05$ ) and HGP (4.88 (SE 0.24) v. 5.91 $(\mathrm{SE} 0.21) \mathrm{mg} / \mathrm{kg}$ per $\mathrm{min} ; P<0.05)$. Fish oil also reduced glucose metabolic clearance rate (6.93 (SE 0.29) v. 8.30 (SE 0.57) $\mathrm{ml} / \mathrm{min})$. Carbohydrate oxidation tended to be less stimulated by exercise after fish oil than after olive oil (12.09 (SE 0.60) v. 13.86 (SE 1.11$) \mathrm{mg} / \mathrm{kg}$ per min; NS). Lipid oxidation tended to be more stimulated by exercise after fish oil (7.34 (SE 0.45) v. 6.85 (SE 0.17) mg/kg per min; NS). Glycaemia, lactataemia, insulinaemia and glucagonaemia were similarly affected by exercise after fish oil and olive oil. Lipolysis at rest was similar after fish oil and olive oil $(2.92$ (SE 0.42) v. 2.94 (SE 0.28$) \mu \mathrm{mol} / \mathrm{kg}$ per min) and similarly stimulated by exercise (6.42 (SE 0.75 ) v. 6.77 (SE 0.72$) \mu \mathrm{mol} / \mathrm{kg}$ per min). It is concluded that fish oil reduced the Rd glucose by $26 \%$ by reducing glucose metabolic clearance rate, possibly by facilitating fat oxidation, and reduced HGP by $21 \%$, possibly by a feedback mechanism.
\end{abstract}

n-3 Fatty acids: Glucose metabolism: Stable isotopes: Fish-oil supplementation

Dietary fatty acids modulate both hepatic glucose production (HGP) and plasma glucose utilisation in rats and in human subjects fed a high-fat diet (Kraegen et al. 1991; Bisschop et al. 2001). A high-saturated-fat diet induces both an increase in gluconeogenesis rate (Commerford et al. 2002) in rats and liver insulin resistance both in rats (Oakes et al. 1997) and in human subjects (Bisschop et al. 2001). When long-chain $n$-3 polyunsaturated fatty acids (PUFA) from fish oil are substituted for saturated fatty acids in the high-fat diet in rats, liver insulin resistance does not occur (Storlien et al. 1987). This protective effect of fish oil could be explained by the inhibiting effect of $n-3$ PUFA on glucose-6-phosphatase (G6Pase) activity. Indeed, n-3 PUFA inhibit G6Pase activity in rat liver (Danièle et al. 1997) and its gene expression (Rajas et al. 2002). Such an inhibiting effect of $n-3$ PUFA on G6Pase could prevent its overexpression and activity during a high-fat diet (Oakes et al. 1997). It should be noted that, in patients with type 2 diabetes, fish-oil supplementation increased gluconeogenesis from glycerol without altering basal HGP (Puhakainen et al. 1995), which might suggest that the acceleration of gluconeogenesis has been counterbalanced by a decrease in G6Pase activity. As well as their effect on HGP, n-3 PUFA also prevent muscle insulin resistance in rats fed a high-fat diet by restoring glucose transport (Jucker et al. 1999; Taouis et al. 2002).

Conversely to what is observed in rats, dietary fish-oil supplementation does not affect either HGP or plasma glucose utilisation in vivo both in healthy human subjects and in patients with type 2 diabetes studied at rest. Indeed, in a previous study, it was observed in healthy human subjects that a 3-week supplementation of the diet with fish oil $(6 \mathrm{~g} / \mathrm{d})$ decreased by $40 \%$ the insulin response to an oral glucose challenge without altering either endogenous glucose production or plasma glucose utilisation. Fat oxidation was $35 \%$ increased and carbohydrate $(\mathrm{CHO})$ oxidation was

\footnotetext{
Abbreviations: CHO, carbohydrate; GLUT, glucose transporter; G6Pase, glucose-6-phosphatase; HGP, hepatic glucose production; PUFA, polyunsaturated fatty acids; $\mathrm{Rd}$ glucose, rate of plasma glucose disappearance; $\mathrm{VO}_{2} \mathrm{max}$, maximal $\mathrm{O}_{2}$ consumption.

* Corresponding author: Mr Jacques Delarue, fax +3329834 78 82, email jacques.delarue@univ-brest.fr
} 
$35 \%$ decreased (Delarue et al. 1996). In patients with type 2 diabetes, fish-oil supplementation does not ameliorate either hepatic or peripheral insulin resistance (Borkman et al. 1989). Thus, a discrepancy exists between observations in rats and in human subjects.

Exercise both prevents and reverses insulin resistance in human subjects (Henriksen, 2002) and in rats fed a high-fat diet (Kim et al. 2000). Such an effect involves glucose transport and insulin signalling in muscle (Henriksen, 2002). During a single bout of exercise of high intensity (65\% maximal $\mathrm{O}_{2}$ consumption; $\mathrm{VO}_{2} \mathrm{max}$ ) performed by healthy subjects, both plasma glucose utilisation and HGP are strongly stimulated (Trimmer et al. 2002). The increase in HGP compensates for the increase in plasma glucose demand of working muscles, which prevents hypoglycaemia. In parallel, both $\mathrm{CHO}$ and fat oxidations are stimulated in response to the increased energy demand of working muscles (Romijn et al. 1993; Trimmer et al. 2002). Training alters fuel selection during exercise by inducing an increase in the stimulation of lipid oxidation and a reduction of the stimulation of $\mathrm{CHO}$ oxidation (Coggan et al. 1990). This alteration of fuel selection is associated with a parallel reduction of the stimulation of plasma glucose utilisation and HGP. The decrease in the stimulation of plasma glucose fluxes after training is attributed to the increased capacity of muscle to oxidise fat (Coggan et al. 1990).

As dietary fish-oil supplementation decreases the stimulation of $\mathrm{CHO}$ oxidation by $35 \%$ and increases fat oxidation by $35 \%$ during an oral glucose load in subjects at rest (Delarue et al. 1996), the present study tested the hypothesis that if fish oil alters fuel selection during exercise as it does at rest, plasma glucose fluxes could be reduced. For that purpose, untrained male subjects were studied during a cycle exercise maintained over $90 \mathrm{~min}$ at $60 \% \mathrm{VO}_{2} \max$ before and after a 3-week dietary fish-oil supplementation.

\section{Materials and methods}

\section{Subjects}

Six active, but untrained, men $(23 \pm 1$ years; $67 \cdot 6 \pm 2 \cdot 7 \mathrm{~kg})$ participated in the study. All subjects were in good health, non-smokers and were not taking any drugs or alcohol. None had a personal or family history of diabetes. Their usual energy intake was estimated from a $7 \mathrm{~d}$ dietary recall. They were asked to maintain their usual physical activity. Ethanol was excluded and coffee intake was restrained. Their $\mathrm{VO}_{2} \max$ was obtained $15 \mathrm{~d}$ before the beginning of the study from a calibrated exercise on an ergometric cycle (2.9 (SE 0.2) litres/min for a power load of 225 (SE 13) W). The experimental protocol was approved by the Ethical Committee of Tours. Before participating in the study, each subject provided informed written consent.

\section{Experimental design}

The duration of the overall study was $40 \mathrm{~d}$, including two consecutive $20 \mathrm{~d}$ periods. During the first period, subjects ingested $6 \mathrm{~g}$ olive oil/d; during the second period, they ingested $6 \mathrm{~g}$ fish oil/d. Olive oil or fish oil was given as six capsules of $1 \mathrm{~g}$ each (two capsules at breakfast, two capsules at lunch and two capsules at dinner). The subjects were unaware of the type of oil contained in the capsules. The two periods with olive-oil or fish-oil supplementation were deliberately not randomised because $n-3$ long-chain fatty acids are incorporated into membranes whose composition remains altered at least 18 weeks after interruption of fish-oil supplementation (Endres et al. 1989). Thus, during such a prolonged period, other factors could have changed, which could have affected metabolic responses to exercise. By using olive oil during the first period, it cannot be excluded that monunsaturated fatty acids are incorporated into membranes. Strictly, the design of the present study leads to a comparison between olive oil and fish oil; olive oil cannot be considered as a 'placebo' of fish oil. During the two periods, the subjects were asked to maintain their usual physical activity. Each period included two consecutive phases; a first $15 \mathrm{~d}$ phase, during which subjects were asked to maintain their usual diet, was followed by a second $5 \mathrm{~d}$ phase, during which the diet was controlled. During this second $5 \mathrm{~d}$ phase, subjects ingested under supervision in our metabolic unit a maintenance isoenergetic diet containing $50 \% \mathrm{CHO}, 30 \%$ fat and $20 \%$ protein, partitioned into three meals. The energy requirements were estimated from resting metabolic rate (calculated according to Weinsier et al. 1992) and a physical factor activity (1.25 or 1.35$)$ estimated from an interview. This value was then adjusted after comparison with the usual energy intake obtained from the subjects' dietary records. This method was chosen to avoid a significant error in the dietary record by using the $7 \mathrm{~d}$ recall, which is known to lack precision. The absence of variation of body weight during the study confirmed that this method was valid. Each meal was prepared individually from usual French food, cooked and weighed $( \pm 1 \mathrm{~g})$ by a dietitian. Blood samples were taken on the last day of each period for the determination of the fatty acid composition of plasma triacylglycerols.

\section{Materials}

Olive oil and fish oil were kindly provided by Groupe Danone (Le Plessis Robinson, France). The composition of these oils is reported in Table 1. $\left[6,6-{ }^{2} \mathrm{H}_{2}\right]$ glucose (99 mol \% excess) and [1,1,2,3,3 $\left.{ }^{2} \mathrm{H}_{5}\right]$-glycerol $(99 \mathrm{~mol} \%$ excess) were purchased from Cambridge Isotopes Laboratory (Andover, MA, USA). Isotopic and chemical purity were checked by GC-MS (Hewlett-Packard 5971, series II; Hewlett-Packard, Les Ulis, France). Tracers were prepared as sterile pyrogen-free solutions in normal saline. The solutions were filtered through a $0.22 \mu \mathrm{m}$ Millipore filter (Millipore Corp., Bedford, MA, USA) during priming and intravenous infusions.

\section{Tests}

Each subject was studied twice, once on day 20, then on day 40 . The tests were conducted over $270 \mathrm{~min}$, in the morning after a $12 \mathrm{~h}$ fast. After voiding, the subjects 
Table 1. Fatty acid content of olive and fish oil (percentage of total fatty acids)*

\begin{tabular}{lcr}
\hline Fatty acids & Olive oil & Fish oil \\
\hline Saturated & & \\
$14: 0$ & Traces & $7 \cdot 8$ \\
$16: 0$ & $10 \cdot 8$ & $19 \cdot 5$ \\
$18: 0$ & $2 \cdot 8$ & $3 \cdot 2$ \\
Others & $0 \cdot 4$ & $1 \cdot 0$ \\
Monounsaturated & & \\
$16: 1$ & $1 \cdot 1$ & $10 \cdot 1$ \\
$18: 1$ & $70 \cdot 4$ & $12 \cdot 6$ \\
$20: 1$ & 0 & $1 \cdot 7$ \\
Others & $0 \cdot 5$ & $1 \cdot 3$ \\
Polyunsaturated & & \\
$18: 2 n-6$ & $8 \cdot 6$ & $1 \cdot 2$ \\
$18: 3 n-6$ & $0 \cdot 6$ & $0 \cdot 4$ \\
$20: 4 n-6$ & 0 & $0 \cdot 9$ \\
$20: 5 n-3$ & 0 & $18 \cdot 5$ \\
$22: 6 n-3$ & 0 & $12 \cdot 0$ \\
Others & 0 & $3 \cdot 0$ \\
\hline
\end{tabular}

${ }^{\star}$ For details of diets and procedures, see p. 778 .

were placed at rest in a bed for $180 \mathrm{~min}$ before performing a 90 min exercise on an ergometer cycle; the exercise was performed at the same absolute workload during the two tests, i.e. $60 \% \quad \mathrm{VO}_{2} \max$ determined before the study. One intravenous catheter was inserted into a wrist vein for the collection of blood samples. Another catheter was inserted into an antecubital vein of the controlateral arm for the infusion of tracers. The rate of plasma glucose disappearance (Rd glucose) and the rate of HGP were traced using $\left[6,6-{ }^{2} \mathrm{H}_{2}\right]$ glucose. A prime-constant infusion of $\left[6,6-{ }^{2} \mathrm{H}_{2}\right]$ glucose (prime $16 \mu \mathrm{mol} / \mathrm{kg}$ body weight, continuous $0.2 \mu \mathrm{mol} / \mathrm{kg}$ per min) was started $180 \mathrm{~min}$ before the exercise period and maintained over $90 \mathrm{~min}$. Then, in order to minimise the variations in isotopic enrichment in ${ }^{2} \mathrm{H}$ of plasma glucose, the infusion rate of $\left[6,6-{ }^{2} \mathrm{H}_{2}\right]$ glucose was increased step-by-step every $30 \mathrm{~min}$ during the exercise period. The infusion rates were $(\mu \mathrm{mol} / \mathrm{kg}$ per min): $\mathrm{T}_{0-30 \text { min }}, 0.4 ; \mathrm{T}_{30-60 \mathrm{~min}}, 0.5 ; \mathrm{T}_{60-90 \mathrm{~min}}, 0.6$. Lipolysis was assessed by using a primed $(1.5 \mu \mathrm{mol} / \mathrm{min})$ continuous $\left(0 \cdot 1 \mu \mathrm{mol} / \mathrm{kg}\right.$ per min) infusion of $\left[1,1,2,3,3-{ }^{2} \mathrm{H}_{5}\right]$ glycerol started from $\mathrm{T}_{-180 \mathrm{~min}}$ and maintained over $270 \mathrm{~min}$.

From $\mathrm{T}_{-60 \mathrm{~min}}$ to $\mathrm{T}_{90 \mathrm{~min}}, \mathrm{CO}_{2}$ and $\mathrm{O}_{2}$ volumes were measured using an open-circuit indirect calorimeter with a ventilated hood as previously described (Delarue et al. 1994). Blood samples were collected every $15 \mathrm{~min}$ from $\mathrm{T}_{-30 \mathrm{~min}}$ to $\mathrm{T}_{90 \mathrm{~min}}$ for determinations of plasma glucose, non-esterified fatty acids, $\beta$-hydroxybutyrate, lactate, insulin and glucagon concentrations, and of plasma isotopic enrichment in ${ }^{2} \mathrm{H}$ of glucose and glycerol. Other blood samples were collected at 0,60 and $90 \mathrm{~min}$ for determination of noradrenaline and adrenaline concentrations. Urine was collected from $\mathrm{T}_{-180 \mathrm{~min}}$ to $\mathrm{T}_{90 \mathrm{~min}}$ for determination of total $\mathrm{N}$.

\section{Sampling and analytical procedures}

Blood samples were collected into heparinised tubes and were immediately spun at $4^{\circ} \mathrm{C}$. Plasma was separated into portions and frozen at $-80^{\circ} \mathrm{C}$ until the time of assay. Urine samples were frozen at $-80^{\circ} \mathrm{C}$ for further determination of total urinary $\mathrm{N}$. Triacylglycerols from oils or plasma were separated and purified by using TLC on silica gel with hexane-diethyl ether-acetic acid (70:30:1, by vol.) as the developing solvent (Bligh \& Dyer, 1959). Fatty acids were determined by direct methylation with boron trifluoride-methanol $\left(90 \mathrm{~min}\right.$ at $\left.100^{\circ} \mathrm{C}\right)$, and spots were scraped from TLC plates. Methyl esters of fatty acids that were obtained were diluted in hexane before separation by GC. Plasma glucose concentrations were measured by the glucose oxidase method using a Beckman glucose analyser 2 (Beckman Instruments, Fullerton, CA, USA). Non-esterified fatty acid concentrations were measured by an enzymic colorimetric method with the use of a commercial kit (NEFA C; Wako Chemicals, Freiburg, Germany). Lactate and $\beta$-hydroxybutyrate concentrations were determined with standard enzymic methods (Bergmeyer et al. 1988). Plasma insulin (INSIRMA; Biosource Europe S.A., Nivelles, Belgium) and glucagon concentrations were measured by a radioimmunoassay. Plasma catecholamines were determined by HPLC. Total urinary $\mathrm{N}$ was determined with the use of Kjeldahl's method (Hawk, 1947). The isotopic enrichment in ${ }^{2} \mathrm{H}$ of plasma glucose was measured by electron impact ionisation on the penta-acetate derivative of glucose and the selective monitoring of ions of $\mathrm{m} / \mathrm{z} 200$ and 202 by using GC-MS (Hewlett-Packard 5971; series II; Hewlett-Packard) as previously described (Delarue et al. 1996). The isotopic enrichment in ${ }^{2} \mathrm{H}$ of plasma glycerol was measured by electron impact ionisation on the glycerol 1,1,2,3,3 tri-acetate derivative and the selective monitoring of ions of $\mathrm{m} / \mathrm{z} 145$ and 148 by using GCMS (Hewlett-Packard 5971, series II; Hewlett-Packard) as previously described by Beylot et al. (1987).

\section{Calculations}

The Rd glucose and HGP were calculated in the non-steady state using Steele's equation (Steele et al. 1956) as modified by De Bodo et al. (1963). The plasma glycerol rate of appearance was also calculated in the non-steady state by using the same equation (De Bodo et al. 1963). The glucose metabolic clearance rate was calculated as the Rd glucose/glycaemia.

Total CHO oxidation and total lipid oxidation were calculated from the volumes of $\mathrm{CO}_{2}$ and $\mathrm{O}_{2}$ and urinary $\mathrm{N}$ excretion using the equations of Livesey \& Elia (1988). It was assumed that $\mathrm{N}$ excretion was the same at rest and during exercise.

Minimal muscle glycogen oxidation was calculated as total CHO oxidation minus Rd glucose (Romijn et al. 1993; Phillips et al. 1997) assuming that $100 \%$ of the glucose that disappeared from the plasma was oxidised during exercise. This calculation would underestimate the minimal rate of glycogen oxidation when plasma glucose is converted directly to lactate or when it is converted into glycogen in muscle (Romijn et al. 1993).

The contribution of plasma glucose to total $\mathrm{CHO}$ oxidation was calculated as $\mathrm{Rd}$ glucose/total $\mathrm{CHO}$ oxidation. 


\section{Statistical methods}

All data are expressed as mean values with their standard errors. Changes in measured or calculated parameters over time during each period were compared using a one-way ANOVA for repeated measures. Comparison of values between the two periods used a two-way ANOVA for repeated measures. When a significant interaction was found, a post hoc test was used to determine pairwise differences. The software used was Statview ${ }^{\text {TM }}$ F (Abacus Concepts, Inc., Berkeley, CA, USA) running on a Powerbook G4 (Apple, Cupertino, CA, USA).

\section{Results}

\section{Weight and dietary intakes}

The weight of the subjects was similar at the end of the olive-oil and fish-oil periods (67.6 (SE 2.7) v. 67.7 (SE 2.6) $\mathrm{kg}$ respectively). Measured energy and macronutrient intakes during the $5 \mathrm{~d}$ controlled diet periods were similar between olive oil and fish oil (Table 2).

\section{Fatty acid content of plasma triacylglycerols}

The total $n-3$ fatty acid content of plasma triacylglycerols was higher after fish oil than after olive oil (6.5 (SE 0.5) v. 2.4 (SE 0.4) \% respectively; $P<0.0001$ ) (Table 3 ).

Table 2. Measured energy and macronutrient intakes during the $5 \mathrm{~d}$ controlled diet phases (oil supplementation excluded) ${ }^{\star}$ (Mean values with their standard errors)

\begin{tabular}{lccccc}
\hline & \multicolumn{2}{c}{ Olive oil } & & \multicolumn{2}{c}{ Fish oil } \\
\cline { 2 - 3 } \cline { 6 - 6 } & Mean & SE & & Mean & SE \\
\hline Energy (MJ/d) & 9.8 & 0.4 & & 9.8 & 0.5 \\
Carbohydrates (g/d) & 292 & 14 & & 292 & 14 \\
Proteins (g/d) & 115 & 5 & & 116 & 6 \\
Lipids (g/d) & 78 & 3 & & 78 & 4 \\
Fatty acids & 55.2 & 2.6 & & 55.3 & 2.6 \\
$\quad$ Saturated (\%) & 33.1 & 1.4 & & 32.9 & 1.5 \\
$\quad$ Monounsaturated (\%) & 11.8 & 0.5 & & 11.8 & 0.6 \\
$\quad$ Polyunsaturated (\%) & 0.213 & 0.001 & & 0.213 & 0.001 \\
P:S & & & & &
\end{tabular}

$\mathrm{P}: \mathrm{S}$, polyunsaturated fatty acids:saturated fatty acids.

${ }^{*}$ For details of diets and procedures, see p. 778.

Table 3. Fatty acid content of plasma triacylglycerols (percentage of total fatty acids) $t$

(Mean values with their standard errors)

\begin{tabular}{lrrrrr}
\hline & \multicolumn{2}{c}{ Olive oil } & & \multicolumn{2}{c}{ Fish oil } \\
\cline { 2 - 3 } \cline { 6 - 7 } Fatty acids & Mean & SE & & Mean & SE \\
\hline Saturated & 35.2 & 1.3 & & 34.8 & 1.7 \\
Monounsaturated & 43.5 & 0.9 & & 39.5 & 1.3 \\
$n-6$ Polyunsaturated & 17.5 & 0.6 & & 17.8 & 0.9 \\
$n-3$ Polyunsaturated & 2.4 & 0.4 & & $6.5^{\star}$ & 0.5 \\
\hline
\end{tabular}

* Mean value was significantly different to that for olive-oil supplementation $(P<0.0001)$.

†For details of diets and procedures, see p. 778 .

\section{Metabolites and hormones}

As compared with rest, glycaemia and insulinaemia decreased over time during exercise (both $P=0.0001$; Figs. 1 and 2). Conversely, glucagonaemia increased over time during exercise $(P<0.05 ;$ Fig. 2). Lactataemia increased for $15 \mathrm{~min}$, then decreased progressively before reaching a plateau at $60 \mathrm{~min}$ (Fig. $1 ; P<0 \cdot 001$ ). Glycaemia, lactataemia, insulinaemia and glucagonaemia were similar between olive oil and fish oil at rest and during exercise. Glycerol was lower at rest and after $90 \mathrm{~min}$ of exercise with fish oil than with olive oil (both $P<0.05$ ) (Table 4). Non-esterified fatty acids and $\beta$-hydroxybutyrate concentrations were higher at the end of exercise as compared with rest $(P<0.05)$ and not different between olive oil and fish oil (Table 4). Adrenaline and noradrenaline were lower in the basal state during fish-oil than during oliveoil supplementation $(P<0 \cdot 05$; Table 5$)$. They increased during exercise and were not different between olive oil and fish oil (Table 5).
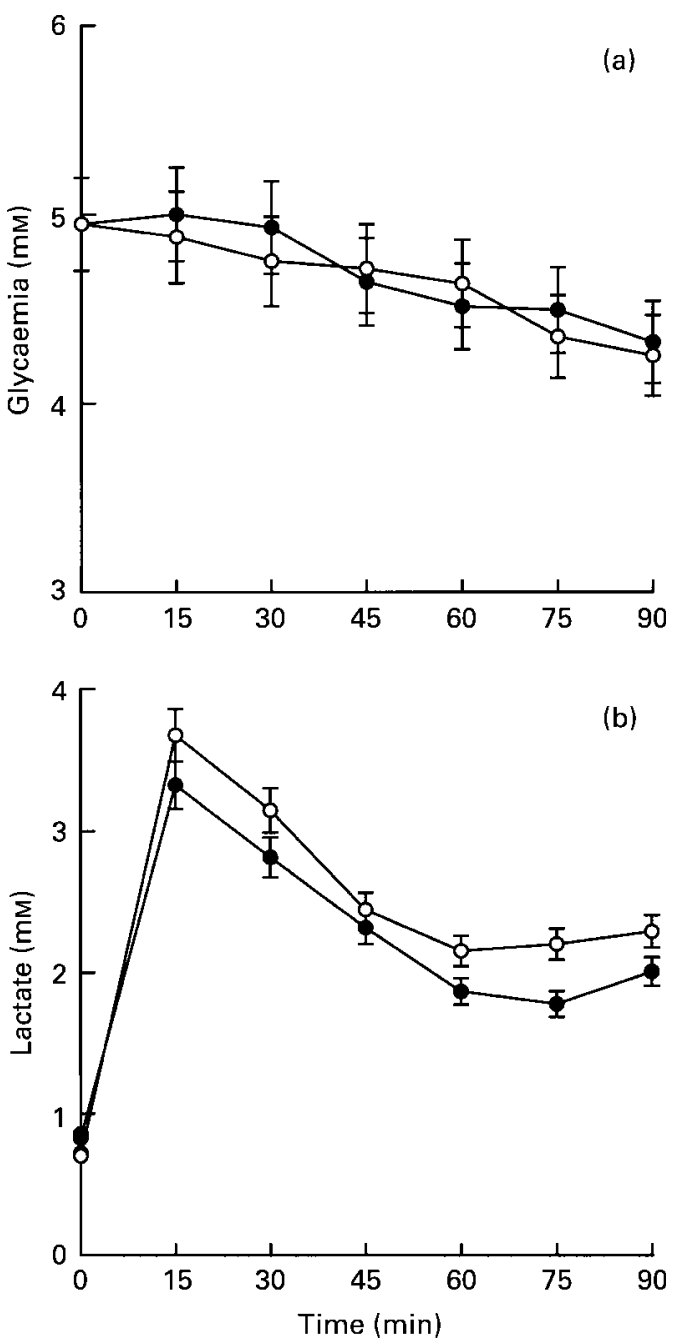

Fig. 1. Plasma glucose (a) and lactate (b) at rest and during cycling exercise ( $60 \%$ maximal $\mathrm{O}_{2}$ consumption) after $20 \mathrm{~d}$ dietary olive-oil (-o-) or $20 \mathrm{~d}$ fish-oil (-๑-) supplementation in six untrained male subjects. Values are means, with their standard errors represented by vertical bars. 

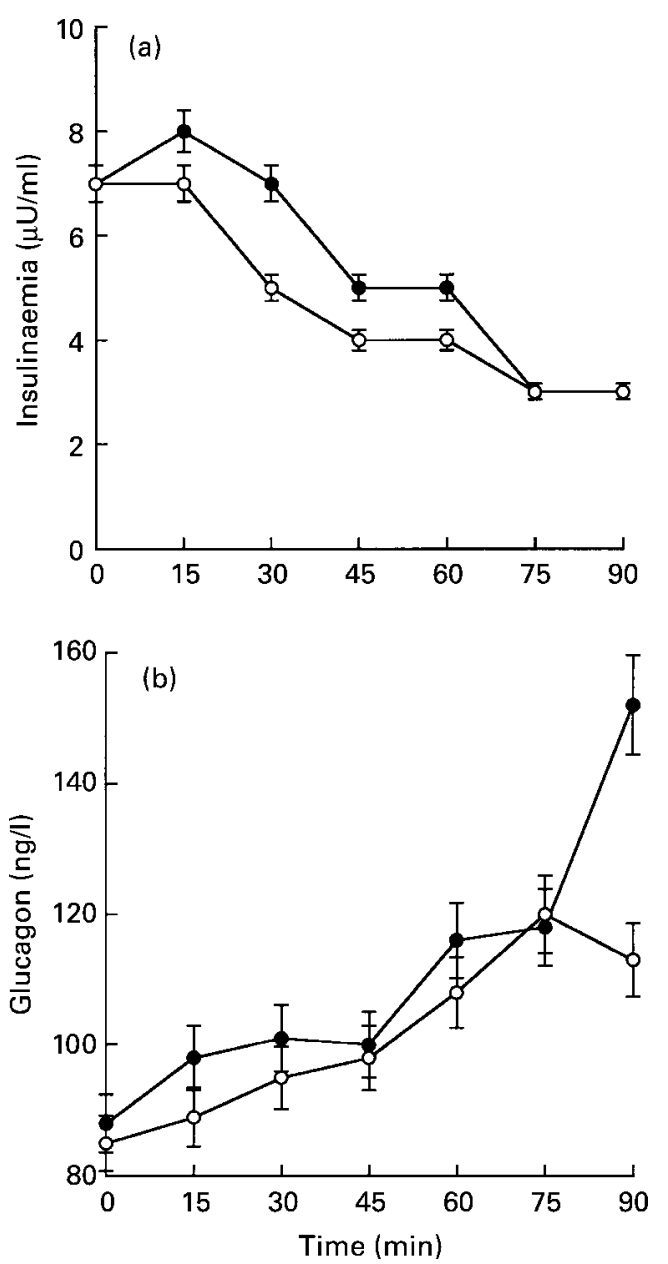

Fig. 2. Plasma insulin (a) and glucagon (b) at rest and during cycling exercise ( $60 \%$ maximal $\mathrm{O}_{2}$ consumption) after $20 \mathrm{~d}$ dietary olive-oil (-o-) or $20 \mathrm{~d}$ fish-oil (-๑-) supplementation in six untrained male subjects. Values are means, with their standard errors represented by vertical bars.

\section{Plasma glucose fluxes}

The Rd glucose increased continuously during exercise $(P=0.0001$; Fig. 3$)$. The Rd glucose was less stimulated from $\mathrm{T}_{60 \text { min }}$ to $\mathrm{T}_{90 \mathrm{~min}}$ after fish oil than after olive oil $(P<0.05)$. HGP increased in parallel with the Rd glucose $(P=0.0001)$ and was less stimulated from $\mathrm{T}_{60 \mathrm{~min}}$ to $\mathrm{T}_{90 \text { min }}$ after fish oil than after olive oil $(P<0 \cdot 05$; Fig. 3$)$. The metabolic clearance rate of glucose increased during exercise $(P<0.001)$ and was lower at $\mathrm{T}_{75 \mathrm{~min}}$ and $\mathrm{T}_{90 \mathrm{~min}}$ after fish oil than after olive oil (Fig. 3).

\section{Plasma glycerol fluxes}

The rates of glycerol appearance and disappearance (Fig. 4) increased continuously during exercise $(P<0.001)$ and were not different between olive-oil and fish-oil periods.

Energy expenditure, substrates oxidation, and muscle glycogen oxidation

Energy expenditure increased steadily at $\mathrm{T}_{15 \mathrm{~min}}$ then remained almost constant around $33 \mathrm{~kJ} / \mathrm{min}$ until $\mathrm{T}_{90 \text { min }}$
$(P<0.001)$ during both olive-oil or fish-oil periods (Table 6). Total fat oxidation increased regularly until $\mathrm{T}_{90 \text { min }}(P<0.001)$ and tended (non-significantly) to be higher after fish oil than after olive oil (Table 6). Total $\mathrm{CHO}$ oxidation increased over time during exercise $(P<0.001)$ and tended to be lower (non-significantly) after fish oil than after olive oil (Table 6). Muscle glycogen oxidation tended to be lower after fish oil than after olive oil (7.1 (SE 0.5) $\mathrm{mg} / \mathrm{kg}$ per min at $\mathrm{T}_{90 \min } v .8 .3$ (SE 1.25) $\mathrm{mg} / \mathrm{kg}$ per min at $\mathrm{T}_{90 \mathrm{~min}}$ respectively) but the difference did not reach statistical significance. The contribution of the plasma disappearance of glucose to total $\mathrm{CHO}$ oxidation was identical between olive oil and fish oil (Fig. 5).

\section{Discussion}

The main observation of the present study is that a supplementation of the usual diet with $6 \mathrm{~g}$ fish oil/d during a period of 3 weeks reduced the stimulation of both HGP $(-21 \%)$ and the Rd glucose $(-26 \%)$ during exercise. The reduction of the stimulation of the $\mathrm{Rd}$ glucose during exercise in the present study was due to a decrease in the metabolic clearance of glucose. This suggests an effect of $n-3$ fatty acids at the level of non-insulin dependent glucose transport. Assuming that $100 \%$ of the glucose that disappeared from the plasma was oxidised, then plasma glucose oxidation was reduced by fish oil. Because the reduction of plasma glucose oxidation with fish oil represented only about $12 \%$ total $\mathrm{CHO}$ oxidation, the impact on total $\mathrm{CHO}$ oxidation was minimal. However, the observation that the contribution of the $\mathrm{Rd}$ glucose (plasma glucose oxidation) to total $\mathrm{CHO}$ oxidation was identical between olive oil and fish oil demonstrates that $\mathrm{CHO}$ oxidation from sources other than plasma glucose was also reduced in the same proportion. As expected, fat oxidation increased during exercise and tended to be higher after fish oil than after olive oil. When calculating the energy equivalent of the difference in fat oxidation between the oliveoil and fish-oil periods, it appears that there is compensation for the decrease in energy from $\mathrm{CHO}$ oxidation. Thus, it can be hypothesised that fish oil induced a slight alteration in fuel selection responsible for the decreased $\mathrm{Rd}$ glucose. The absence of a significant difference of whole-body substrates oxidation could be explained by the lower sensitivity of the measurement of substrates oxidation as compared with the measurement of plasma glucose fluxes. It is noteworthy that the alteration of fuel selection induced by fish oil during exercise was less marked than that induced during an oral load taken in the resting state (Delarue et al. 1996). During an oral glucose load, the alteration of fuel selection mainly depends on the effect of insulin whereas during exercise the alteration of fuel selection is mainly independent from insulin. Thus, it can be hypothesised that the effect of fish oil on fuel selection implicates mainly pathways activated by insulin. It is unlikely that fish oil altered the Rd glucose by a decreasing effect on glucose transport. Indeed, fish oil prevents the defect of muscle glucose transport during high-fat diet treatment in rats (Storlien et al. 1996) and does not alter the $\mathrm{Rd}$ glucose during an oral glucose load in spite of a $40 \%$ lower insulin response in healthy 
Table 4. Plasma metabolites and plasma glycerol fluxes during basal and exercise conditionsł (Mean values with their standard errors)

\begin{tabular}{|c|c|c|c|c|}
\hline \multirow[b]{2}{*}{ Metabolites and hormones } & \multicolumn{2}{|c|}{ Basal } & \multicolumn{2}{|c|}{ Exercise $\left(T_{90} \mathrm{~min}\right)$} \\
\hline & Mean & SE & Mean & SE \\
\hline \multicolumn{5}{|l|}{ Glycerol $(\mu \mathrm{M})$} \\
\hline Isoenergetic diet + olive oil & 72 & 9 & $337 \dagger$ & 23 \\
\hline Isoenergetic diet + fish oil & $42^{*}$ & 9 & $223^{*} \dagger$ & 21 \\
\hline \multicolumn{5}{|l|}{ NEFA $(\mu \mathrm{M})$} \\
\hline Isoenergetic diet + olive oil & 448 & 119 & $1067 \dagger$ & 125 \\
\hline Isoenergetic diet + fish oil & 321 & 95 & $836 \dagger$ & 59 \\
\hline \multicolumn{5}{|l|}{$\beta$-Hydroxybutyrate $(\mu \mathrm{M})$} \\
\hline Isoenergetic diet + fish oil & 85 & 28 & $181 \dagger$ & 44 \\
\hline \multicolumn{5}{|l|}{ Ra glycerol ( $\mu \mathrm{mol} / \mathrm{kg}$ per min) } \\
\hline Isoenergetic diet + olive oil & 2.94 & 0.28 & 7.92† & 0.7 \\
\hline Isoenergetic diet + fish oil & 2.92 & 0.42 & $7.02 \dagger$ & \\
\hline \multicolumn{5}{|l|}{ Rd glycerol ( $\mu \mathrm{mol} / \mathrm{kg}$ per min) } \\
\hline Isoenergetic diet + olive oil & 2.94 & 0.28 & $6 \cdot 77 \dagger$ & 0.72 \\
\hline Isoenergetic diet + fish oil & 2.92 & 0.42 & $6.42 \dagger$ & 0.75 \\
\hline
\end{tabular}

NEFA, non-esterified fatty acids; Ra glycerol, glycerol rate of appearance; Rd glycerol, glycerol rate of disappearance.

*Mean value was significantly different to that for olive-oil supplementation $(P<0.05)$.

† Mean value was significantly different to that for the basal (resting) condition $(P<0.05)$.

$\ddagger$ For details of diets and procedures, see p. 778.

Table 5. Plasma adrenaline and noradrenaline concentrations during basal and exercise conditions (nM)‡

(Mean values with their standard errors)

\begin{tabular}{|c|c|c|c|c|c|c|}
\hline \multirow[b]{2}{*}{ Catecholamines } & \multicolumn{2}{|c|}{ Basal } & \multicolumn{2}{|c|}{ Exercise $\left(T_{60 \mathrm{~min}}\right)$} & \multicolumn{2}{|c|}{ Exercise $\left(T_{90} \mathrm{~min}\right)$} \\
\hline & Mean & SE & Mean & SE & Mean & SE \\
\hline \multicolumn{7}{|l|}{ Adrenaline } \\
\hline Isoenergetic diet + olive oil & $1 \cdot 17$ & 0.22 & $1.93 \dagger$ & 0.31 & 1.43 & 0.15 \\
\hline \multicolumn{7}{|l|}{ Noradrenaline } \\
\hline Isoenergetic diet + olive oil & 3.00 & 0.64 & $8 \cdot 61 \dagger$ & $2 \cdot 20$ & $4 \cdot 44$ & 0.42 \\
\hline Isoenergetic diet + fish oil & $1.85^{*}$ & 0.20 & $6.52 \dagger$ & 1.45 & $7.59 \dagger$ & 2.49 \\
\hline
\end{tabular}

${ }^{*}$ Mean value was significantly different to that for olive-oil supplementation $(P<0.05)$.

$\dagger$ Mean value was significantly different to that for the basal (resting) condition $(P<0.05)$.

$\ddagger$ For details of diets and procedures, see p. 778 .

human subjects (Delarue et al. 1996). In addition, if fish oil does not reverse peripheral insulin resistance in patients with type 2 diabetes, it does not reduce the $\mathrm{Rd}$ glucose during a hyperinsulinaemic clamp (Borkman et al. 1989; Rivellese et al. 1996). However, exercise stimulates glucose transport in muscle by inducing the recruitment of a specific pool of glucose transporters (GLUT) 4 different from that stimulated by insulin (Hayashi et al. 1997). Also, exercise induces hexokinase II activity strongly associated to GLUT4 (Koval et al. 1998), and so it might be possible that fish oil altered the pathway of translocation of this specific pool of GLUT4 and/or hexokinase II activity. It has been shown that long-chain PUFA decrease hexokinase activity in the heart (Stewart \& Blakely, 2000), but no demonstration of such an effect in skeletal muscle has been reported. Recently, it has been suggested that glucose uptake during exercise could be driven by the activation of AMP-activated protein kinase (Winder et al. 1999). Whether fish oil could alter this pathway remains to be studied. The subjects in the present study were tested twice at the same workload. A difference in $\mathrm{O}_{2}$ consumption capacity is unlikely since fish oil does not modify $\mathrm{VO}_{2} \max$ (Raastadt et al. 1997). An alteration of blood flow or its redistribution is also unlikely. Indeed, plasma catecholamines were similar between the two tests on one hand and eicosapentaenoic acid, a long-chain $n$-3 PUFA contained in fish oil, increases peripheral vasodilation, which should have increased the Rd glucose (Tagawa et al. 1999).

The reduction of HGP stimulation matched the reduction in the Rd glucose so that glycaemia was similar during exercise with olive as with fish oil. The parallel decrease in plasma glucose utilisation and in HGP implies a coordinate effect of fish oil on plasma glucose transport and on intrahepatic glucose metabolism. The decrease in stimulation of HGP with fish oil probably results from an adaptation to the decreased stimulation of the Rd glucose via feedback mechanisms involving the central nervous 

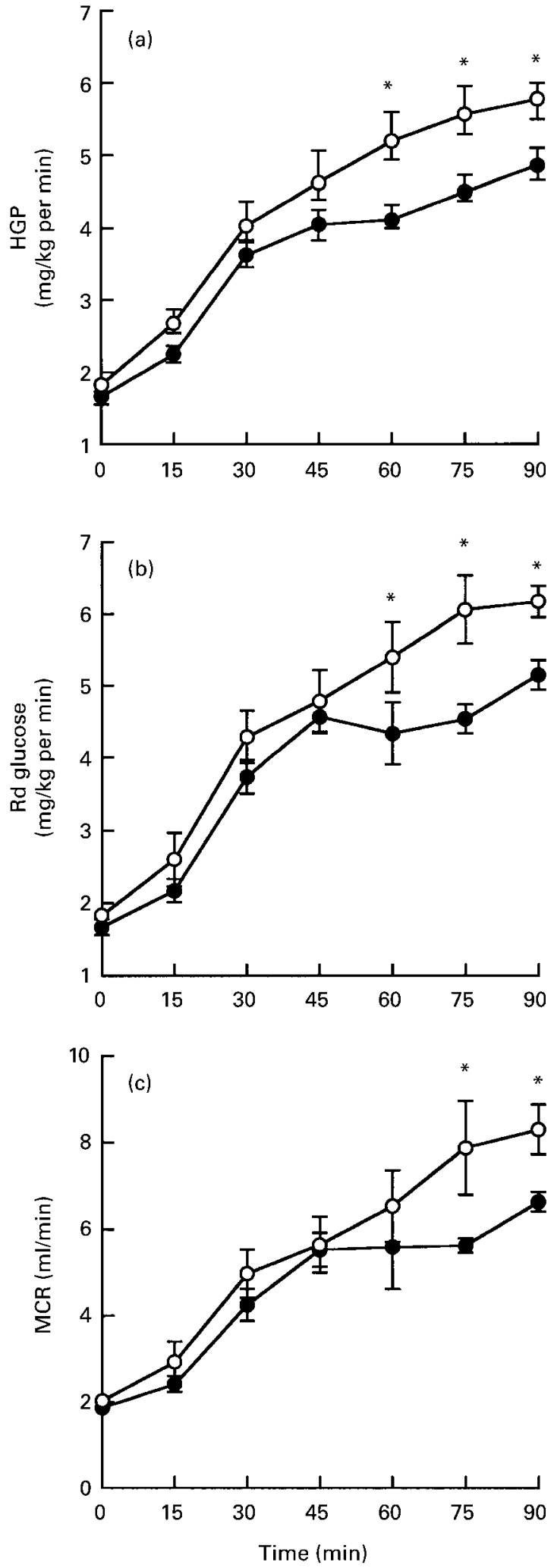

Fig. 3. Hepatic glucose production (HGP) (a), rate of plasma glucose disappearance ( $R d$ glucose) (b) and plasma glucose metabolic clearance rate (MCR) (c) at rest and during cycling exercise (60\% maximal $\mathrm{O}_{2}$ consumption) after $20 \mathrm{~d}$ dietary olive-oil (-o-) or $20 \mathrm{~d}$ fish-oil (-๑-) supplementation in six untrained male subjects. Values are means, with their standard errors represented by vertical bars. *Mean value was significantly different to that for fish-oil supplementation $(P<0.05)$.
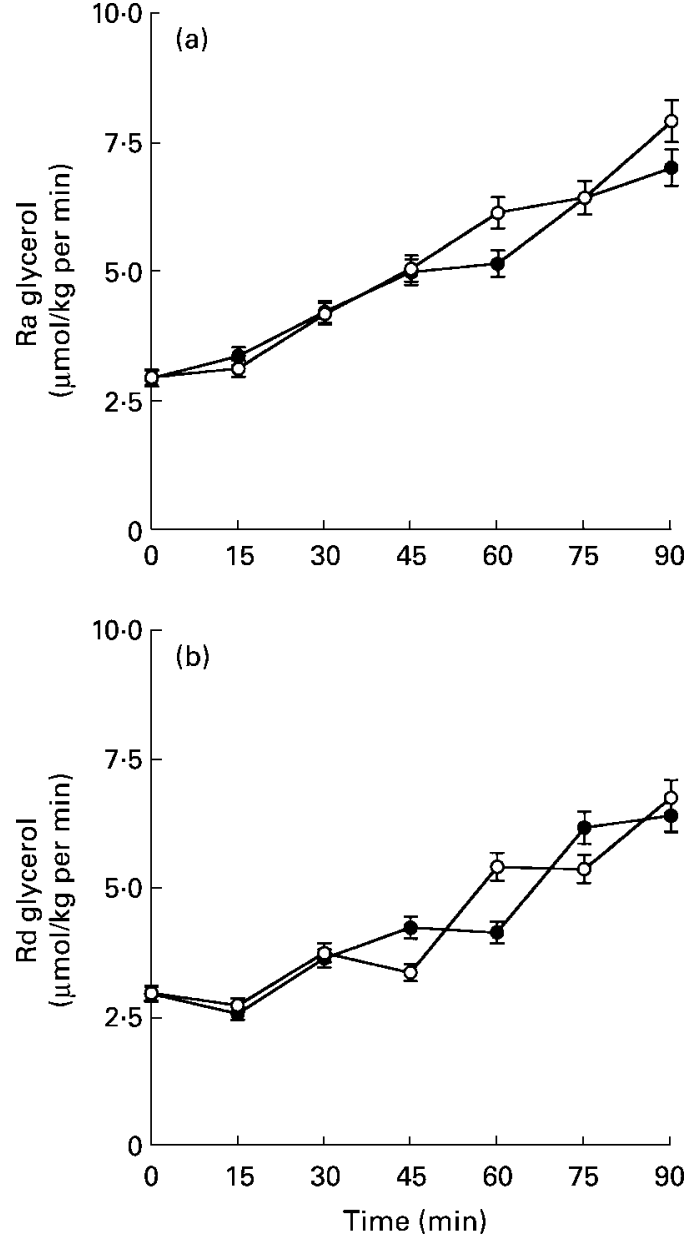

Fig. 4. Rates of plasma glycerol appearance (Ra glucose) (a) and disappearance (Rd glucose) (b) at rest and during cycling exercise ( $60 \%$ maximal $\mathrm{O}_{2}$ consumption) after $20 \mathrm{~d}$ dietary olive-oil (-o-) or $20 \mathrm{~d}$ fish-oil (-๑-) supplementation in six untrained male subjects. Values are means, with their standard errors represented by vertical bars.

system or other modulators (Wasserman, 1995). In the present study, if such an adaptation occured, it was unlikely due to a lower sympathetic activity because plasma catecholamines did not differ between fish-oil and olive-oil periods during exercise although they were lower after fish oil at rest. The mediators of such a feedback mechanism during exercise without or with fish oil have not yet been discovered. The effect of fish oil on HGP could have resulted from a decrease in gluconeogenesis and/or glycogenolysis on one hand and/or from a decrease in flux through G6Pase on the other hand. A decrease in stimulation of the gluconeogenesis rate is very unlikely considering that plasma lactate concentrations as well as the rates of glycerol appearance and disappearance were similar with or without fish oil. In addition, factors regulating the gluconeogenesis rate, i.e. the insulin:glucagon ratio and liver fatty acids oxidation (estimated by $\beta$-hydroxybutyrate concentrations) were similar between the two tests. A decrease in liver glycogenolysis cannot be ruled out. However, it should be noted that long-chain n-3 PUFA stimulate glycogen phosphorylase in hepatocytes (Gomez-Munoz et al. 1991), which does not plead for a 
Table 6. Energy expenditure and substrates oxidation during basal and exercise conditions $†$

(Mean values with their standard errors)

\begin{tabular}{|c|c|c|c|c|}
\hline & \multicolumn{2}{|c|}{ Basal } & \multicolumn{2}{|c|}{ Exercise $\left(T_{90 \mathrm{~min}}\right)$} \\
\hline & Mean & SE & Mean & SE \\
\hline \multicolumn{5}{|c|}{ Energy expenditure (kJ/min) } \\
\hline Olive oil & 5.98 & 1.05 & $34.43^{*}$ & 2.51 \\
\hline Fish oil & 5.94 & 0.46 & $33 \cdot 47^{\star}$ & $2 \cdot 18$ \\
\hline \multicolumn{5}{|c|}{$\mathrm{CHO}$ oxidation (mg/kg per min) } \\
\hline Olive oil & 1.57 & 0.25 & $13 \cdot 86^{*}$ & $1 \cdot 11$ \\
\hline Fish oil & $1 \cdot 21$ & 0.15 & $12 \cdot 09^{*}$ & 0.60 \\
\hline \multicolumn{5}{|c|}{ Lipid oxidation (mg/kg per min) } \\
\hline Olive oil & 0.97 & 0.09 & $6 \cdot 85^{\star}$ & 0.17 \\
\hline Fish oil & 1.12 & 0.09 & $7 \cdot 34^{\star}$ & 0.45 \\
\hline
\end{tabular}

$\mathrm{CHO}$, carbohydrate

* Mean value was significantly different to that for the basal (resting) condition $(P<0.05)$.

†For details of diets and procedures, see p. 778.

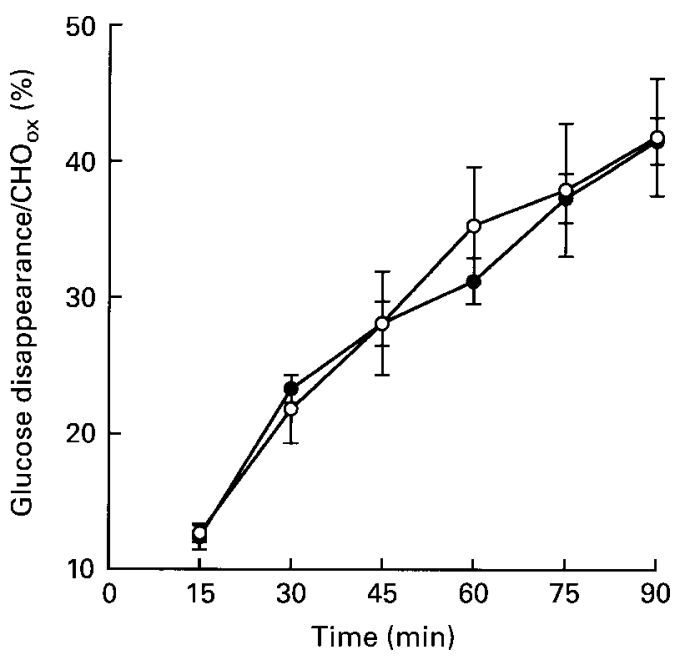

Fig. 5. Contribution of plasma glucose disappearance to total carbohydrate oxidation $\left(\mathrm{CHO}_{\text {ox }}\right)$ during cycling exercise $(60 \%$ maximal $\mathrm{O}_{2}$ consumption) after $20 \mathrm{~d}$ dietary olive-oil (-o-) or $20 \mathrm{~d}$ fish-oil (-๑-) supplementation in six untrained male subjects. Values are means, with their standard errors represented by vertical bars.

decrease in liver glycogenolysis in the present study. Finally, a decreased flux through G6Pase cannot be completely ruled out because long-chain $n$-3 PUFA have been demonstrated to decrease G6Pase expression and activity in rat liver (Danièle et al. 1997; Rajas et al. 2002).

Glycaemia decreased similarly during exercise in both experiments because glucose utilisation was slightly higher than hepatic glucose production. This phenomenon has been reported before (Trimmer et al. 2002) and confirms that the stimulation of HGP cannot compensate for the high rates of plasma glucose utilisation when liver glycogen content has been compromised by fasting and exercise.

The present study considered the possibility that the decreased plasma glucose fluxes observed after fish-oil supplementation might be due to an adaptation to physical exercise due to the repetition of the testing procedure over time. The non-random performance of exercise tests in the design of the study was used because of the long washout period (18 weeks, i.e. 4.5 months) required for the complete disappearance of $n-3$ fatty acids in plasma membranes (Endres et al. 1989). Performing two tests after such a very long washout period entailed the important risk of a change in other factors, which could have confounding effects on the metabolic response to exercise. Such factors include intercurrent illness, change in dietary habit because of seasonal variation or holidays, and change in physical activity due possibly to holidays or other causes. Another risk was the possible dropout of subjects who might be less inclined to attend for the second test after a long wait. This lack of randomisation is very unlikely to explain the effect that was observed after fish oil because caution was taken to try to prevent as much as possible the contribution of confounding factors. Indeed, the subjects received olive-oil then fish-oil supplementation during the same length of time, i.e. $20 \mathrm{~d}$ each. The subjects' body weight was similar at the end of each period implying a similar energy balance during the two periods. The diet was strictly controlled during the last $5 \mathrm{~d}$ of each period as confirmed by the similar measured intakes. The resting values of substrates and hormones concentrations as well as of resting energy expenditure were not different in the morning of each of the two tests in accordance with a similar metabolic status. Moreover, a possible effect of the previous test on the second test was very unlikely because the time that elapsed between the two tests had a duration of $20 \mathrm{~d}$. This period of time is sufficient to return to previous metabolic status; the exercise had a short duration $(90 \mathrm{~min})$ and was not repeated over many days so that a training effect was very unlikely to occur. The subjects were asked to maintain their usual physical activity during the two periods, which was obtained as confirmed by anamnesis. Green et al. (2000) observed that a single training session elicited metabolic adaptations similar to those reported after training of long duration. However, the type of training session performed by the subjects in the Green et al. (2000) study was very different from the exercise performed by the subjects in the present study. In the Green et al. (2000) study, the training session involved $6 \mathrm{~min}$ each hour at $90 \%$ $\mathrm{VO}_{2} \max$ for $16 \mathrm{~h}$ and not continuous exercise over 90 min at $60 \% \mathrm{VO}_{2}$ max. Last, as a part of another study (J Delarue et al. unpublished results), the subjects from the present study were studied $5 \mathrm{~d}$ after the first exercise of the present study, while absorbing over that $5 \mathrm{~d}$ a high-CHO diet. The Rd glucose and HGP were not different (data not shown) indicating that the reduction of plasma glucose fluxes was not modulated by repetition of exercise or the high-CHO diet, which reinforces the very possibility of a specific effect of fish oil. Thus, it can be said with confidence that in the present study, fish oil did reduce plasma glucose fluxes during exercise.

In summary, a 3-week fish-oil consumption in untrained subjects decreases the Rd glucose by $26 \%$ and HGP by $21 \%$ during $90 \mathrm{~min}$ cycling at $60 \% \quad \mathrm{VO}_{2} \mathrm{max}$, which could be related to a tendency to an increasing effect of fish oil on fat oxidation substituting for $\mathrm{CHO}$ oxidation. The parallel decrease of the Rd glucose and HGP is probably due to a feedback mechanism of adaptation of HGP to the decreased Rd glucose. 


\section{Acknowledgements}

This work was supported by a grant from Groupe Danone. The authors thank Professor Luc Tappy (Lausanne) for his very helpful discussion of the results. The technical assistance of Mrs Objois was deeply appreciated.

\section{References}

Bergmeyer HU, Bergmeyer J \& Grassl JM (1988) Methods of Enzymatic Analysis, 3rd ed., vol. 4. Weinheim, Germany: Verlag Chemie.

Beylot M, Martin C, Beaufrère B, Riou JP \& Mornex R (1987) Determination of steady state and nonsteady-state glycerol kinetics in humans using deuterium-labeled tracer. J Lipid Res 28, 414-422.

Bisschop PH, de Metz J, Ackermans MT, et al. (2001) Dietary fat content alters insulin-mediated glucose metabolism in healthy men. Am J Clin Nutr 73, 554-559.

Bligh EG \& Dyer WJ (1959) A rapid method of total lipid extraction and purification. Can J Biochem Physiol 37, 911-917.

Borkman M, Chisholm DJ, Furler SM, et al. (1989) Effects of fish oil supplementation on glucose and lipid metabolism in NIDDM. Diabetes 38, 1314-1319.

Coggan AR, Kohrt WM, Spina RJ, Bier DM \& Holloszy JO (1990) Endurance training decreases plasma glucose turnover and oxidation during moderate-intensity exercise in men. J Appl Physiol 68, 990-996.

Commerford SR, Ferniza JB, Bizeau ME, Thresher JS, Willis WT \& Pagliassotti MJ (2002) Diets enriched in sucrose or fat increase gluconeogenesis and G-6-Pase but not basal glucose production in rats. Am J Physiol 283, E545-E555.

Danièle N, Bordet JC \& Mithieux G (1997) Unsaturated fatty acids associated with glycogen may inhibit glucose-6-phosphatase in rat liver. J Nutr 127, 2289-2292.

De Bodo RC, Steele R, Altszuler N, Dunn A \& Bishop JS (1963) On the hormonal regulation of carbohydrate metabolism: studies with ${ }^{14} \mathrm{C}$ glucose. Recent Prog Horm Res 19, 445-448.

Delarue J, Couet C, Cohen R, Bréchot JF, Antoine JM \& Lamisse F (1996) Effects of fish oil on metabolic responses to fructose and glucose oral loads in healthy humans. Am J Physiol 270, E353-E362.

Delarue J, Maingourd C, Lamisse F, Garrigue MA, Bagros P \& Couet C (1994) Glucose oxidation after a peritoneal and an oral glucose load in dialyzed patients. Kidney Int $\mathbf{4 5}$, $1147-1152$.

Endres S, Ghorbani R, Kelley VE, et al. (1989) The effect of dietary supplementation with $\mathrm{n}-3$ polyunsaturated fatty acids on the synthesis of interleukin-1 and tumor necrosis factor by mononuclear cells. $N$ Engl J Med 320, 265-271.

Gomez-Munoz A, Hales P \& Brindley DN (1991) Unsaturated fatty acids activate glycogen phosphorylase in cultured rat hepatocytes. Biochem J 276, 209-215.

Green H, Tupling R, Roy B, O'Toole D, Burnett M \& Grant S (2000) Adaptations in skeletal muscle exercise metabolism to a sustained session of heavy intermittent exercise. Am J Physiol 278, E118-E126.

Hawk PB (1947) Kjeldahl method. In Practical Physiological Chemistry, pp. 814-822. Toronto, Canada: Blakinston.

Hayashi T, Wojtaszewski JFP \& Goodyear LJ (1997) Exercise regulation of glucose transport in skeletal muscle. Am J Physiol 273, E1039-E1051.

Henriksen EJ (2002) Effects of acute exercise and exercise training on insulin resistance. J Appl Physiol 93, 788-796.
Jucker BM, Cline GW, Barucci N \& Shulman GI (1999) Differential effects of safflower oil versus fish oil feeding on insulin-stimulated glycogen synthesis, glycolysis, and pyruvate dehydrogenase flux in skeletal muscle. Diabetes $\mathbf{4 8}$, $134-140$.

Kim CH, Youn JH, Park JY, et al. (2000) Effects of high-fat diet and exercise training on intracellular glucose metabolism in rats. Am J Physiol 278, E977-E984.

Koval JA, DeFronzo RA, O'Doherty RM, et al. (1998) Regulation of hexokinase II activity and expression in human muscle by moderate exercise. Am J Physiol 274, E304-E308.

Kraegen EW, Clark PW, Jenkins AB, Daley EA, Chisholm DJ \& Storlien LH (1991) Development of muscle insulin resistance after liver insulin resistance in high fat fed rats. Diabetes $\mathbf{4 0}$, $1397-1403$.

Livesey G \& Elia M (1988) Estimation of energy expenditure, net carbohydrate utilization, and net fat oxidation and synthesis by indirect calorimetry: evaluation of errors with special reference to the detailed composition of fuels. Am J Clin Nutr 47, 608-628.

Oakes ND, Cooney GJ, Camilleri S, Chisholm DJ \& Kraegen EW (1997) Mechanisms of liver and muscle insulin resistance induced by chronic high-fat feeding. Diabetes 46, 1768-1774.

Phillips SM, Green HJ, Grant SM, et al. (1997) Effect of acute plasma volume expansion on substrate turnover during prolonged low-intensity exercise. Am J Physiol 273, E297-E304.

Puhakainen I, Ahola I \& Yki-Jarvinen H (1995) Dietary supplementation with n-3 fatty acids increases gluconeogenesis from glycerol but not hepatic glucose production in patients with non-insulin-dependent diabetes mellitus. Am J Clin Nutr 6, $121-126$

Raastad T, Hostmark AT \& Stromme SB (1997) Omega-3 fatty acid supplementation does not improve maximal aerobic power, anaerobic threshold and running performance in well trained soccer players. Scand J Med Sci Sports 7, 25-31.

Rajas F, Gautier A, Bady I, Montano S \& Mithieux G (2002) Polyunsaturated fatty acyl coenzyme A suppress the glucose6-phosphatase promoter activity by modulating the DNA binding of hepatocyte nuclear factor 4 alpha. J Biol Chem 277, 15736-15744

Rivellese AA, Maffettone A, Iovine C, et al. (1996) Long-term effects of fish oil on insulin resistance and plasma lipoproteins in NIDDM patients with hypertriglyceridemia. Diabetes Care 19, 1207-1213.

Romijn JA, Coyle EF, Sidossis LS, et al. (1993) Regulation of endogenous fat and carbohydrate metabolism in relation to exercise intensity and duration. Am J Physiol 265, E380-E391.

Steele R, Wall JS, De Bodo RC \& Altszuler N (1956) Measurement of size and turn over rate of body glucose pool by the isotope dilution method. Am J Physiol 187, E15-E24.

Stewart JM \& Blakely JA (2000) Long chain fatty acids inhibit and medium chain fatty acids activate mammalian cardiac hexokinase. Biochim Biophys Acta 1484, 278-286.

Storlien LH, Baur LA, Kriketos AD, et al. (1996) Dietary fats and insulin action. Diabetologia 39, 621-631.

Storlien LH, Kraegen EW, Chisholm DJ, Ford GL, Bruce DG \& Pascoe WS (1987) Fish oil prevents insulin resistance induced by high fat feeding in rats. Science 237, 885-888.

Tagawa H, Shimokowa H, Tagawa T, Kuroiwa-Matsumoto M, Hirooka Y \& Takeshita A (1999) Long-term treatment with eicosapentaenoic acid augments both nitric oxide-mediated and non-nitric oxide-mediated endothelium-dependent forearm vasodilation in patients with coronary artery disease. J Cardiovasc Pharmacol 33, 633-640.

Taouis M, Dagou C, Ster C, Durand G, Pinault M \& Delarue J (2002) $\mathrm{N}-3$ polyunsaturated fatty acids prevent the defect of insulin receptor signaling in muscle. Am J Physiol 282, E664-E671. 
Trimmer JK, Schwarz JM, Casazza GA, Horning MA, Rodriguez N \& Brooks GA (2002) Measurement of gluconeogenesis in exercising men by mass isotopomer distribution analysis. J Appl Physiol 93, 233-241.

Wasserman DH (1995) Regulation of glucose fluxes during exercise in the postabsortive state. Ann Rev Physiol 57, $191-218$.
Weinsier R, Schutz Y \& Bracco D (1992) Reexamination of the relationship of resting metabolic rate to fat-free mass and to the metabolically active components of fat-free mass in humans. Am J Clin Nutr 55, 790-794.

Winder WW \& Hardie DG (1999) AMP-activated protein kinase, a metabolic master switch: possible roles in type 2 diabetes. Am J Physiol 277, E1-E10. 